\title{
CHARACTERIZATION OF KARST TERRAIN USING GEOPHYSICAL METHODS BASED ON SINKHOLE ANALYSIS: A CASE STUDY OF THE ANINA KARSTIC REGION (BANAT MOUNTAINS, ROMANIA)
}

Laurentiu Artugyan

Department of Geography, West University of Timisoara, Blvd. V. Parvan 4, Timisoara 300223, Timis, Romania, lau_artugyan@yahoo.com

Adrian C. Ardelean

Department of Geography, West University of Timisoara, Blvd. V. Parvan 4, Timisoara 300223, Timis, Romania, adrian.ardelean@e-uvt.ro

\section{Petru Urdea}

Department of Geography, West University of Timisoara, Blvd. V. Parvan 4, Timisoara 300223, Timis, Romania, petru.urdea@e-uvt.ro

\begin{abstract}
To understand karst topography, we must determine both the nature and the factors that are defining dissolution processes in soluble rocks, as well as the drainage network resulting from these processes. The goal of this paper is to understand the underground drainage direction configuration and, also, the factors that are involved in surface water drainage of the Anina karstic region.
\end{abstract}

In this study we used two complementary geophysical methods, spontaneous potential (SP) and ground penetrating radar (GPR), applied in 5 sinkholes with a funnel shaped aspect. Four of these sinkholes are circular and one of them is elongated NW-SE direction. Three of the studied sinkholes are representing a chain of sinkholes orientated west-east.

SP data describe the surface drainage, indicating drainage direction and/or moisture accumulation points. The GPR investigation utilizes electromagnetic pulses for the investigation of subsurface dielectric properties. GPR offers an image of the underground, showing possible bedding planes, in this case mostly along northsouth orientations. Besides, in two GPR profiles, we could identify an object that could be a cavity, in that point were on SP grid the values indicate small values, pointing out a link between those two geophysical results. Using SP and GPR methods we were able to show that the bottoms of these depressions are retaining more humidity and soil. In addition, the GPR profiles outlined several subsurface "objects", at a depth ranging between 20 and 40 meters, which need a more thorough analysis.
Our future work is intended to enrich our field data using SP and GPR methods, to compare with our first results. Also, we intend to integrate electrical resistivity tomography measurements in our analysis for better subsurface characterization.

\section{Introduction}

In Romania limestone represents almost $2 \%$ of its surface. The largest and most compact area of carbonate rocks in Romania is within the Reşiţa-Moldova Nouă Synclinorium, situated in the SW of the country, in the unit called Banat Mountains.

Karst terrain results from rock masses dissolution, having as a consequence an effective underground flow (Waltham et al., 2005). To understand karst topography, we must determine both the nature and the factors that are defining dissolution processes in karst soluble rocks as well as the drainage network resulted from these processes. (Ford, Williams, 2011).

The density and size of sinkholes indicate the degree of dissolution that geological substrate has undergone locally (Shofner et al., 2001). The fractures and their orientation in a karstic area give important knowledge regarding the drainage network, due to the fact that the karst system depends highly upon them (Chalikakis et al., 2011).

The study case of this paper is located in one of Banat Mountains' subunits, Aninei Mountains. This approach is a comparative study using spontaneous potential (SP) and ground penetrating radar (GPR) as geophysical 
methods. SP is a passive and an electrical geophysical method, which quantifies naturally occurring electrical fields at the Earth's surface.

The self-potential surveying is based upon measuring the spontaneous or natural potentials developed in the earth by electrochemical actions between minerals and subsurface fluids or by electrokinetic processes involving the flow of ionic fluids (Sharma, 2002).

Also SP in the subsurface is caused by a number of processes that are not well understood at this time (Reynolds, 1997).

In recent years the SP method has found increasing use in geothermal, environmental, and engineering applications to help locate and delineate sources associated with the movement of thermal fluids and groundwater.

The spontaneous potential method has been used for many years in karstic areas (Stevanovic, Dragisic, 1998; Lange, 1999; Rozycki et al., 2006; Guichet et al., 2006; Jardani et al., 2007; Jardani et al., 2009, Jouniaux et al., 2009; Robert et al., 2011).

GPR is a non-destructive geophysical tool that can produce a continuous profile in cross section or record features underground without drilling, boring, or digging. GPR profiles are normally used to assess the location and depth of underground objects, and investigating the presence or the continuity of the natural subsoil conditions (Apel and Dezelic, 2005). The resulting GPR image (also called a radargram) is very similar to a seismic reflection profile. Acquisition of data by means of GPR is based on the propagation, reflection and distribution of high-frequency electromagnetic waves (generally from 10 to $1000 \mathrm{MHz}$ ) to the underground. Using GPR's in karst areas partially covered with alluvial deposits is not very common, mainly due to alluvial deposits, clay content, which is hindering the penetration depth of GPR systems (Anchuela et al., 2008). Therefore, the results obtained will depend upon the type of soil and its degree of saturation, compaction, mineralogy, and also on the frequency of antennas used (Anchuela et al., 2009). If the study area contains clayey soils, it is recommended the GPR method should not be used in the sinkhole investigation (Zisman et al, 2013).

Studies to detect cavities using the GPR method were done by Chamberlain et al. (2000), Kadioglu and Ulugergerli
(2012). Other goals for GPR applications in karstic regions are sinkhole detection and characterization: Anchuela et al. (2010), for sinkholes detection near Zaragoza (Spain), Anchuela et al. (2013) with a paper on the current development of sinkholes, Gutiérrez et al. (2011) combined GPR with different techniques for sinkhole characterization, and Nouioua et al. (2013) using GPR and ERT. Al-fares et al. (2002) developed a study for a karst aquifer structure involving also GPR measurements. A study that involves both methods used in this paper was done by Carpenter et al. (2013) near Cancun, Mexico.

In Romania, geophysical methods are not often used for karst investigations, even if there are many interesting karstic regions. There are two papers using resistivity methods, Mafteiu (1991) and Mitrofan et al. (2008), vertical electrical sounding (VES) using Schlumberger and pole-dipole arrays.

Mafteiu (1991) observed the vertical and horizontal plane of the fracturing effect that predetermines the development of the Cave of Padiș, and in the Padiş Plateau he identified the border between fissured limestone and compact limestone. Mitrofan et al. (2008) managed to delineate with succes a concealed flow path in Hercules spring (Cerna Valley).

The goal of this paper is to analyze the terrain of the Anina karstic region to understand the underground drainage direction and the factors that are involved in surface water drainage. This study is based on field data collection during five field campaigns, from May 2013 to November 2014.

\section{Study Area}

The Anina karstic region is situated in the South-West of Romania, within the Banat Mountains, as shown shaded in yellow in Figure 1.

Geologically, the study area is located in the central part of the Reşiţa - Moldova Nouă Synclinorium, the largest and most compact, homogeneous structure covered by carbonate rocks in Romania (Orăşeanu and Iurkiewicz, 2010).

We developed our study on the Mărghitaş Plateau, a suspended karstic plateau without surface water drainage, located in the northern part of the Anina karstic region (Figure 2). 


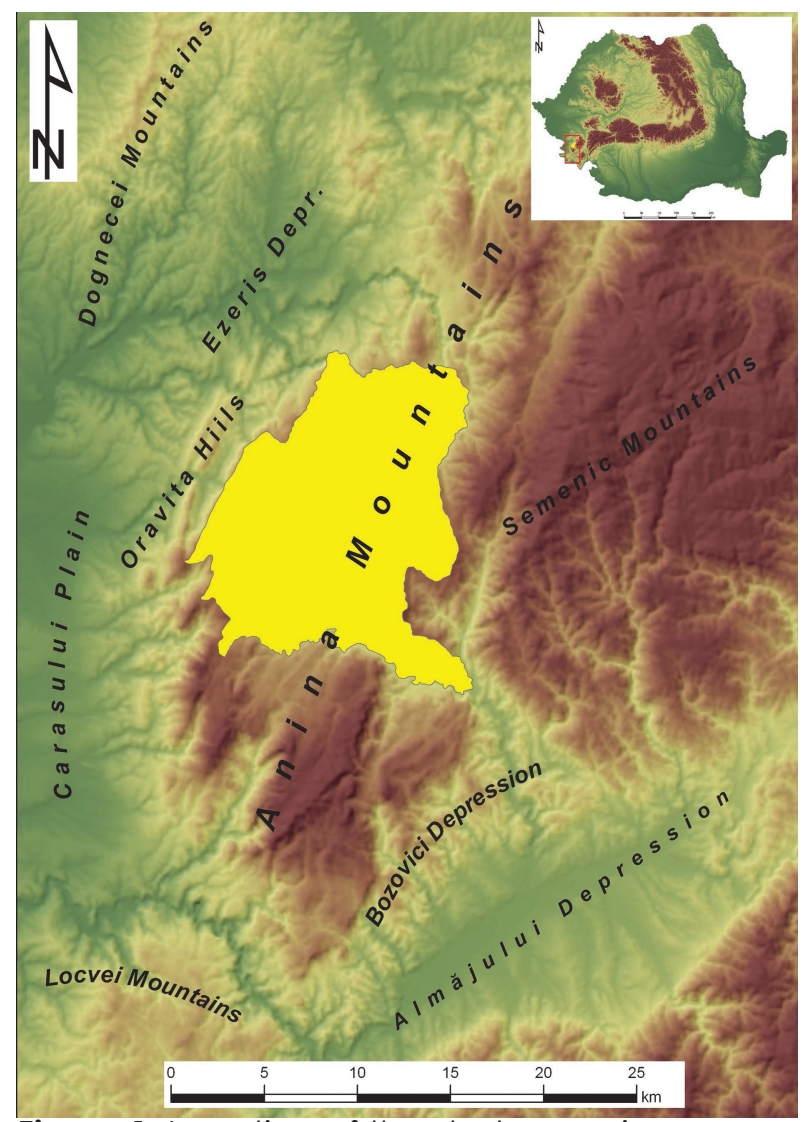

Figure 1. Location of the study area in Romania and in the Banat Mountains. The karst area is shaded in yellow.

There are many surface karstic landforms that may be seen: sinkholes, sinkholes vallyes, blind valleys, dry valleys, karrens, and karren fields (Figure 3).

\section{Field Methods}

The characterization of karst regions requires specific knowledge of both surface and those forms of underground features, and application of the geophysical methods are an option to study the subsurface in connection with the surface landforms. One of these methods, which is also used in the analysis of the groundwater, especially in karst areas, is spontaneous potential (SP). The second method that completes our geophysical approach is GPR.

For SP data, we used two Petieau nonpolarizing electrodes, a fixed electrode and a mobile one. The measurements were made with a digital multimeter, Voltcraft VC 850. We measured SP at 11 sites, repeating measurements 2 or 3 times, in different seasons and atmospheric conditions for comparison purposes. Our approaches for SP measurements are represented by profiles with N-S and E-W orientations and grids. Each

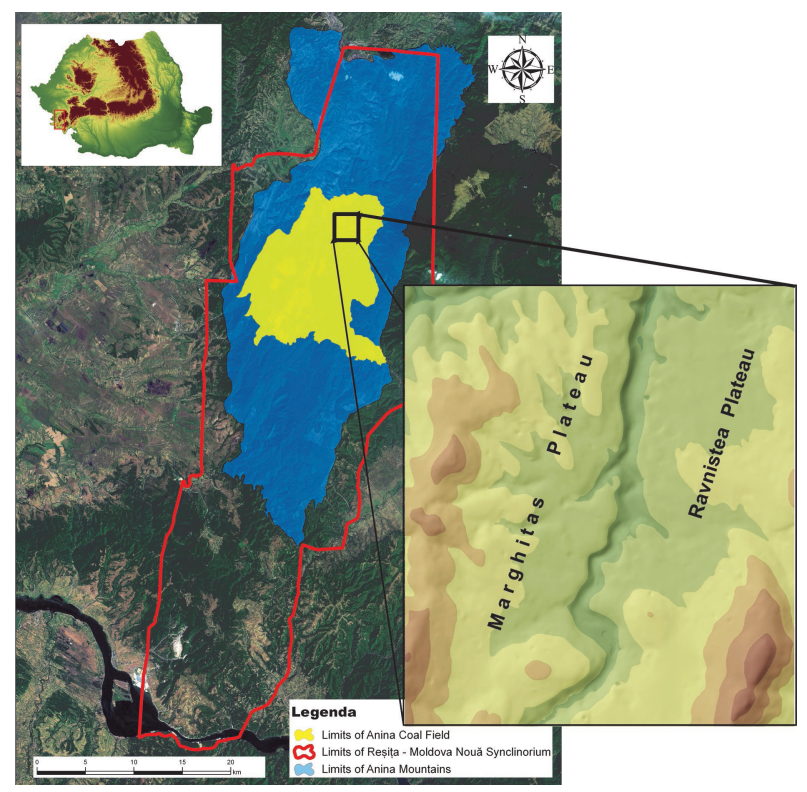

Figure 2. Location of the Mărghitaş Plateau and Anina karstic region within the structural area of the Reşiț - Moldova Nouă Synclinorium.

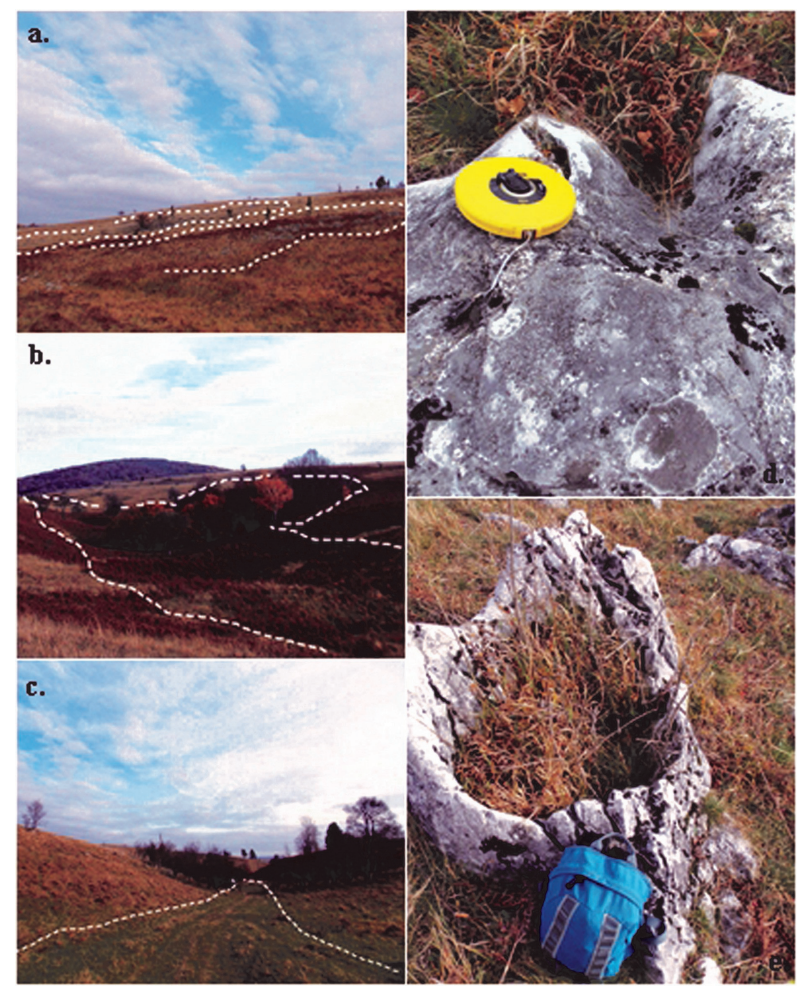

Figure 3. Karst features on Mărghitaş Plateau: a. karren field; b. sinkhole valley; c. dry valley; d., e. karrens. 
electrode was placed inside a hole, $10 \mathrm{~cm}$ deep in the soil and after 1 minute we noted the value indicated on the voltmeter (in $\mathrm{mV}$ ) and then we moved the mobile electrode. The station spacing for the mobile electrodes was $5 \mathrm{~m}$.

For the GPR method, we used a MALA RAMAC Georadar with two antennas, $50 \mathrm{MHz}$ and $25 \mathrm{MHz}$. Because we developed our study in a karstic area, our goal was to identify voids on the radargrams below the locations of the SP anomalies. Because in the study area other geophysical studies are missing, we chose as a first approach to use an antenna that give a deeper penetration in the subsoil, trying to have better image regarding the underground in the Mărghitaş karstic plateau. Based on previous study on limestone and due to the fact that the RTA antennas are of compact type, no Common Midpoint (CMP) or Wide Angle Reflection and Refraction (WARR), thus an overall wave velocity of $0.12 \mathrm{~m} / \mathrm{ns}$ was used for the depth conversion of the radar signal (Kadioglu and Ulugergerli, 2012; Apel and Dezelic, 2005). GPR results are represented by 11 profiles, $50 \mathrm{MHz}$ frequency with a depth of 22 meters, 8 profiles with the $25 \mathrm{MHz}$ antenna with a depth of penetration of 46 meters and 1 profile also with the 25 $\mathrm{MHz}$ antenna with a depth of 54 meters. In the next section of this paper, we present the results obtained. We focus on 3 sites using the $25 \mathrm{MHz}$ antenna, being the most representative in these measurements. The measurements presented in this paper were made near the Mărghitaș Hotel (Figure 4).

\section{Results \\ Site 1}

SP results for the sinkhole in Site 1 were obtained in May 2013 and November 2013. Measurements obtained after the first campaign express mostly negative values, with some positive values. In the autumn 2013 all SP values were positive, excepting one borehole where we obtained a negative value.

The field measurements were interpolated based on the $5 \mathrm{~m}$ distance between holes, rasterized and contoured using ArcGIS 10 software developed by ESRI (http:// www.esri.com/software/arcgis), obtaining the raster presented in Figure 5. Water flow in this sinkhole has similar direction as the tectonic fault orientation, N-S or NW-SE. This observation is highlighted in the contoured images, but is clearer in the data obtained in November

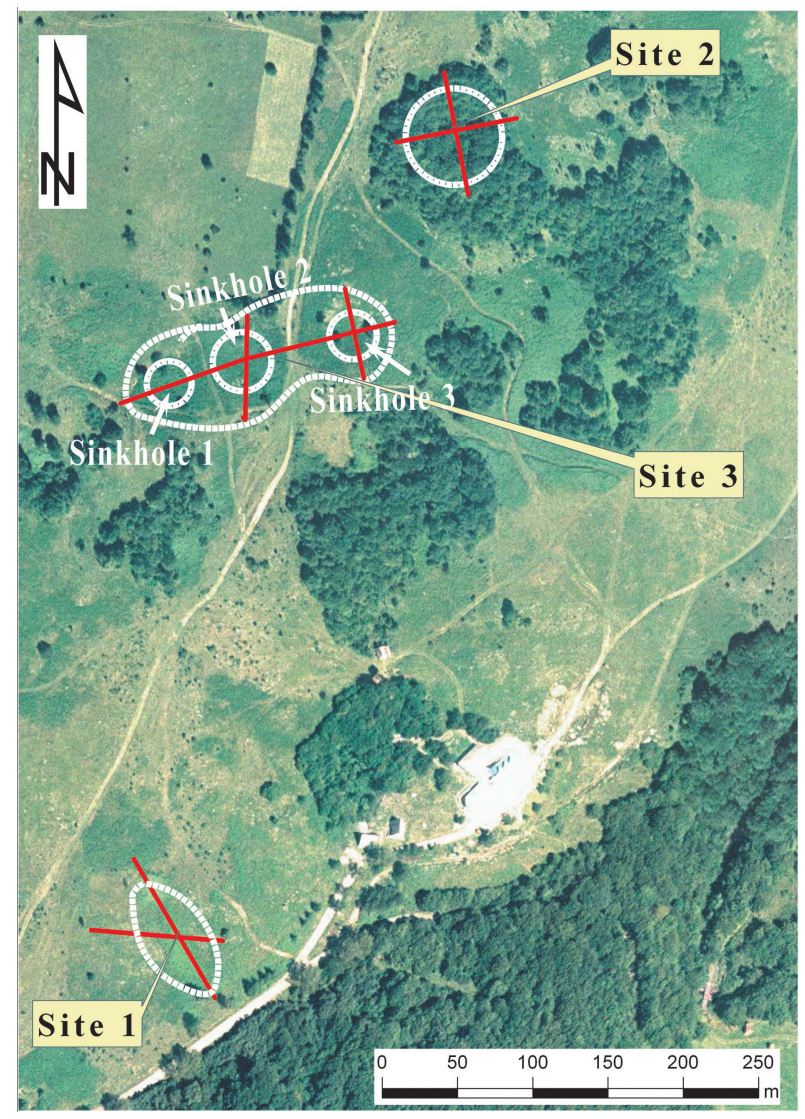

Figure 4. Location of GPR measurement sites.

2013 (Figure 5b), where we can notice that the middle of the sinkhole is accumulating humidity (red) and the drainage direction is mostly north-south, as we will obtain also in GPR measurements for bedding planes orientation.

In May 2013 (Figure 5a) SP measurements indicate that on the boundaries of the sinkhole there is a direction of water infiltration, due to negative anomalies. At the bottom of the sinkhole, larger values suggest water retention, a function of the flat terrain and also based on the deep soil cover. In May 2013 the values where more different, alternating negative values (especially on the border of the sinkhole, where karrens are present) with positive values (in the middle of the sinkhole).

The SP values obtained in November 2013 are more homogeneous, due to weather conditions. The campaign was done after many months of uniform precipitations. In Figure $5 \mathrm{~b}$ is more obvious the bottom of the sinkhole, where are the largest values, indicating the stagnancy of water (Artugyan and Urdea, 2014). 


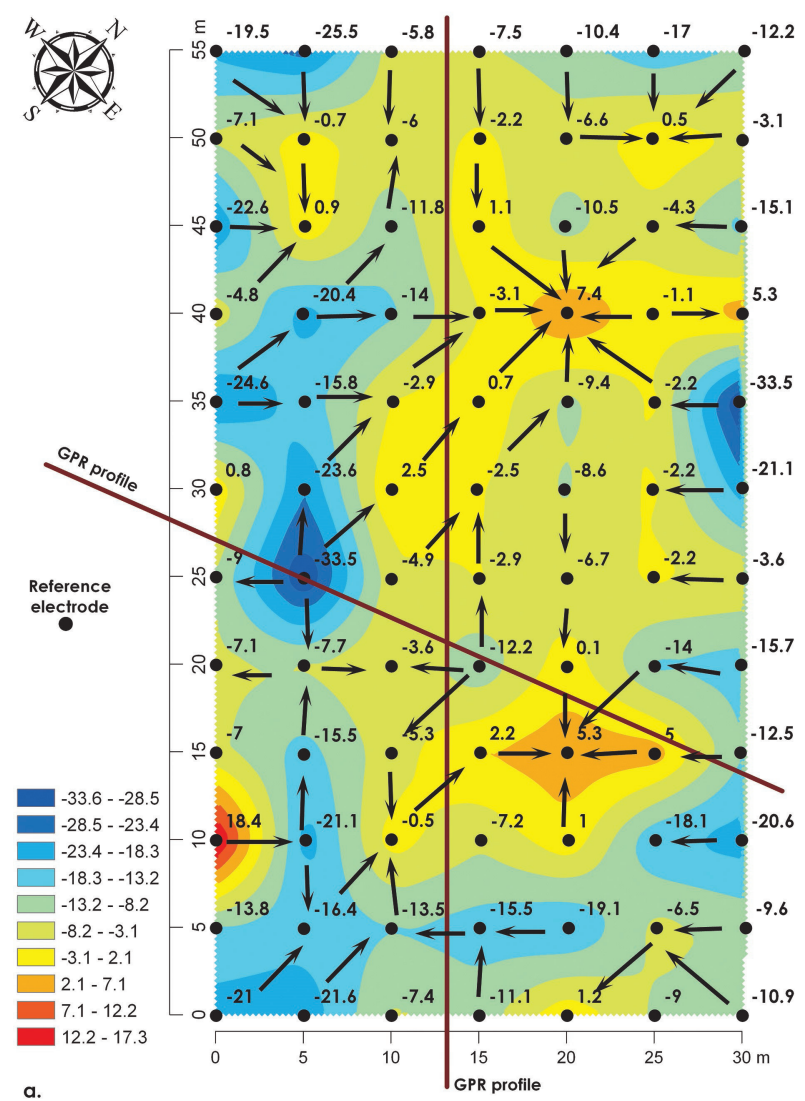

Figure 5a. Spontaneous Potential measurements in Site 1 in May 2013.

For Site 1 (Figure 6) we used two antennas, $25 \mathrm{MHz}$ and $50 \mathrm{MHz}$ to observe the difference on the radargrams. The $50 \mathrm{MHz}$ profiles have shallower penetration, a higher resolution, but in our investigation on these sites didn't help us too much, being more difficult to interpret the radargrams and losing in depth. After we obtained the radargrams with the $50 \mathrm{MHz}$ antenna, we chose that for the other sites to use only $25 \mathrm{MHz}$ antenna because we needed a deeper penetration trying to observe in the underground certain cavities, bedrock bedding planes, fractures or maybe the groundwater level.

On the $25 \mathrm{MHz}$ profiles, we notice that the sinkhole is very clearly observed, because we realized the profile longer than sinkhole's diameters, to observe the difference in the radar signals. The first radargram (Figure 7) shows very well the bottom of the sinkhole and also the slopes, and at the end of it, we notice the buried karrens or small voids. Besides, we notice a continuous signal that we consider as a bedding plane of the area.

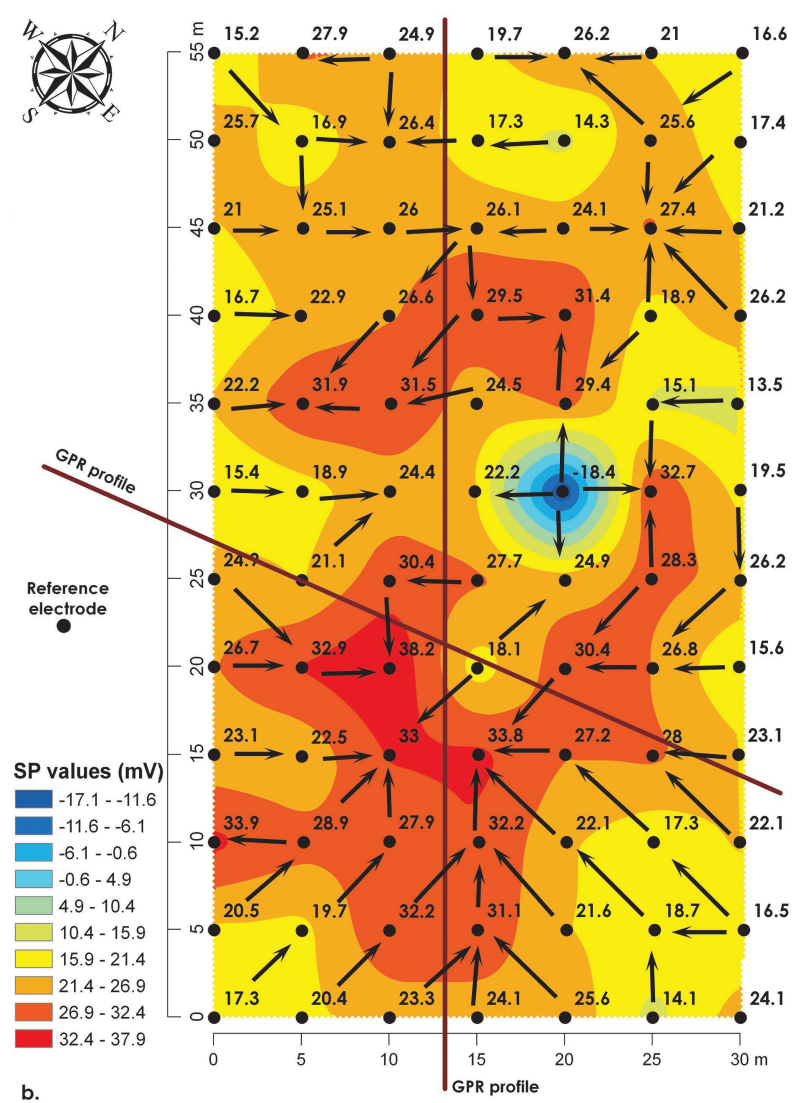

Figure 5b. Spontaneous Potential measurements in Site in November 2013.

\section{Site 2}

Site 2 features a large sinkhole, with the east-west diameter of 70 meters and the north-south diameter by 60 meters. The SP measurements were made in two campaigns, October 2013 and November 2014. In October 2013 the SP values present negative values, with some positive anomalies, showing that at that period, after several weeks without precipitation, the

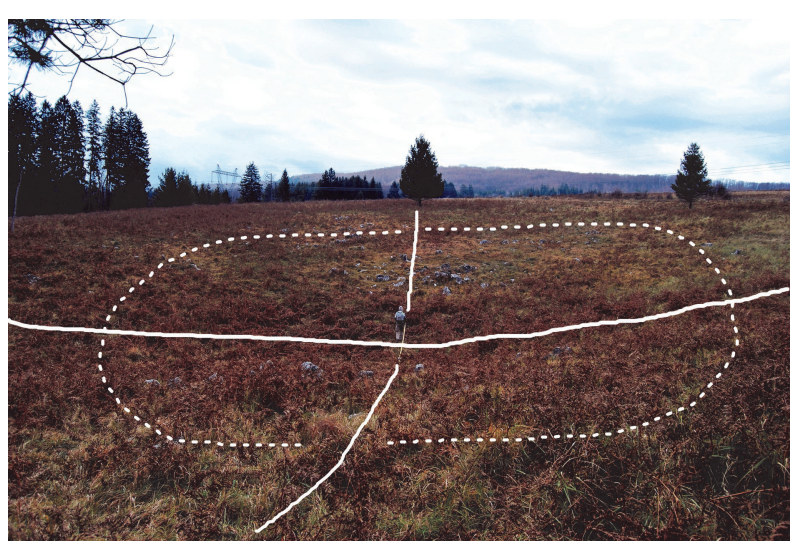

Figure 6. Site 1 and the location of GPR profiles. 


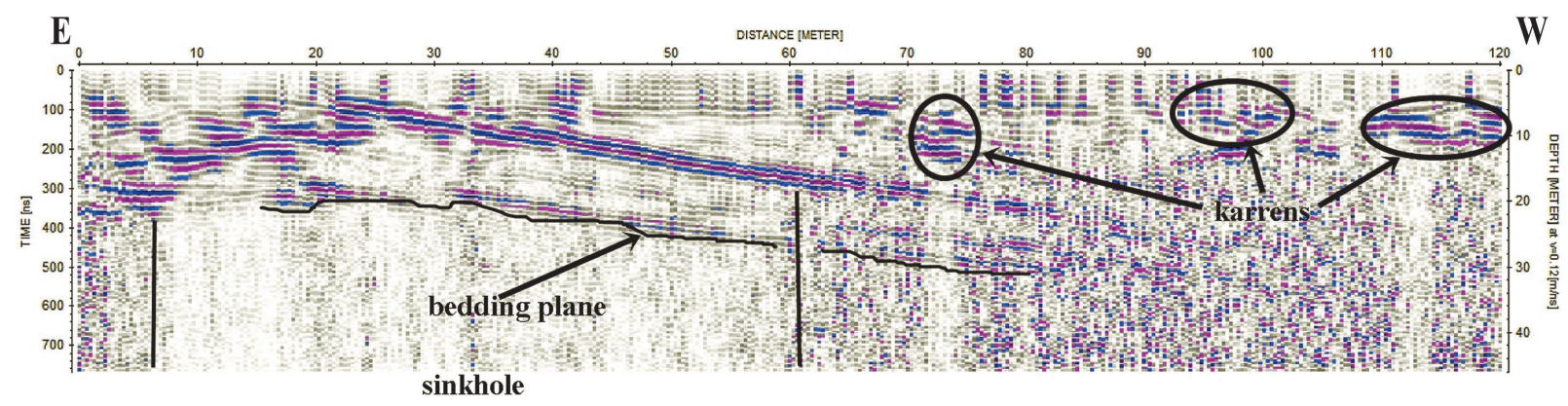

Figure 7. GPR profile (25 MHz antenna) in Site 1 on east-west direction.

surface is not well moistured, being favorable for rapid flow into the underground. In November 2014 the values are positive, indicating that the drainage is more stable, the soil is more saturate with water. The middle of the sinkhole presents the highest values on E-W direction.

On the E-W orientation, in the middle of the sinkhole the SP presents values indicating accumulation, as we expect to obtain in the middle of these karstic depressions where the bottom is filled with thinner soil and the humidity presents higher values (Figure 8 ). The same situation is observed also in November 2014, but this time the measurements were realized after a week with higher precipitation in the area and the SP values are negative, indicating that the surface drainage is more unstable. Again SP values indicate that in the middle this geophysical method shows accumulating moisture. Also, we can notice that in both profiles there are two negative anomalies at 9 and 12 meters from the starting point of the profile and at 63 meters. These anomalies are showing that at that point the drainage is more rapid, being possibly linked to certain voids underground.

On the north-south orientation (Figure 9) the profile is more sinuous, presenting many negative anomalies, but we notice that in both campaigns at the point located at 24 meters there is a negative anomaly, possibly indicating a void in the underground where water is more rapidly drained. The north-south profile is not very expressive for this sinkhole, the bottom of it being not very obvious as for the east-west profile. This fact could indicate that on the north-south orientation the fractures in the bedrock are more developed, determining a certain behavior in water drainage. If we take into account the fault main orientation in the area, NNW-SSE, maybe we could find an explanation for the aspect of those N-S profiles.

We can observe that in both profiles in the middle of the sinkhole is well highlighted on E-W orientation, with the highest values, indicating moisture accumulation and water retention due to thick soil. On N-S direction, we may observe a negative anomaly at $24 \mathrm{~m}$ from the start of the profile in both campaigns, which could indicate a void in the underground which quickly drains water from the surface. Even if on N-S direction the profiles are not very smooth, we can notice that except those negative anomalies at $24 \mathrm{~m}$, the bottom of the sinkholes indicate the largest values, showing the tendency to retain moisture for a long time.

The aspect of this sinkhole (Figure 10) gives as the interpretation of the GPR results: in the middle there is a large accumulation of materials (organic, soil) and on the slopes the karrens are also observed on the GPR profiles.

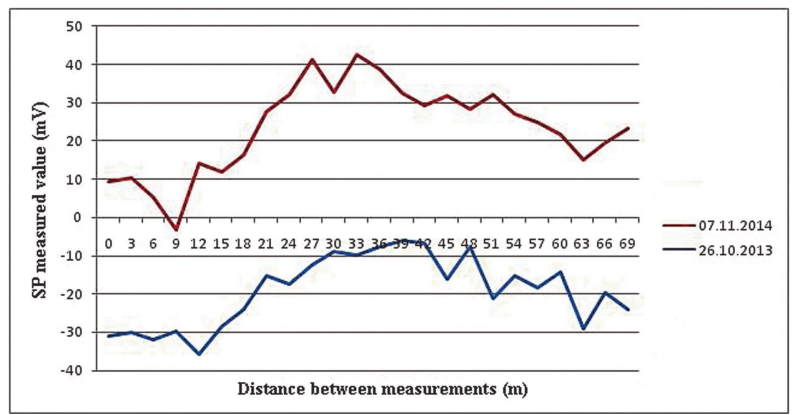

Figure 8. Spontaneous Potential measurements at Site 2 (east-west orientation).

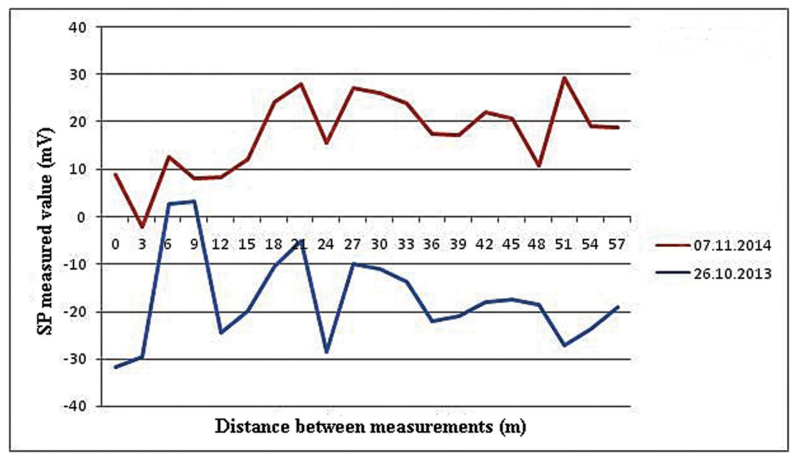

Figure 9. Spontaneous Potential measurements at Site 2 (north-south orientation). 
Because is known that clay may perturb the GPR signals, we intend to employ in this site study electrical resistivity tomography, to describe accurately the underground and validate the GPR results.

Also, we observe that as on the first reflection radargram we could identify the countinuos GPR signal, considering that it should be also bedding planes, this area being a strong faulted zone.

GPR profiles for Site 2 are designed to better explain the SP results and to give an image of the underground of this sinkhole. We can notice that GPR profiles are similar to both SP profiles, meaning that the W-E profile, shown in Figure 11, describes a smooth hyperbola for

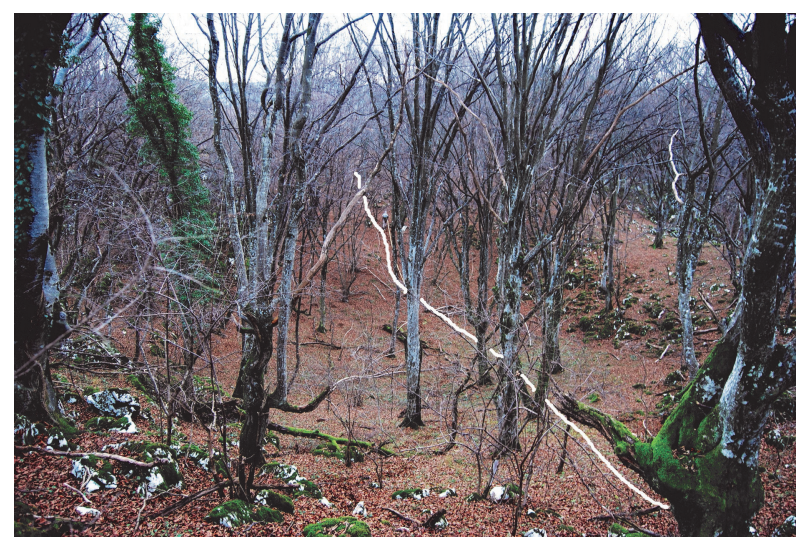

Figure 10. GPR measurements at Site 2. the sinkhole, with highest radar signals in the middle, but the second GPR profile, for N-S orientation (Figure 12), has many anomalies between the surface and 25 meters depth. These anomalies are also observed on the SP profiles.

\section{Site 3}

Site 3 is a chain of three sinkholes with west-east direction. Sinkhole 1 is the smallest one and less deep, the second one is the largest one, and Sinkhole 3 is the deepest one of this chain of sinkholes.

Sinkhole 3 consists of a circular sinkhole, a funnel shaped one, with a swallow hole in the middle. SP values were obtained at the beginning of October 2014, after several days of precipitation. The results show that in the middle, in the smaller sinkhole the water is staying for a long time, indicating moisture accumulation (larger values of SP data). Also, near the edges of the sinkhole, where karrens are present, the drainage is more rapidly, due to these rocks and thin soil. SP values indicate that the surroundings the swallow hole inside the large one presents the tendency of rapid flow into the swallow hole direction (smaller values of SP measurements) (Figure 13).

For GPR profiles, this site means a chain of three sinkholes (Figure 14) where we intend to observe on the radargrams the boundary of these karstic depressions

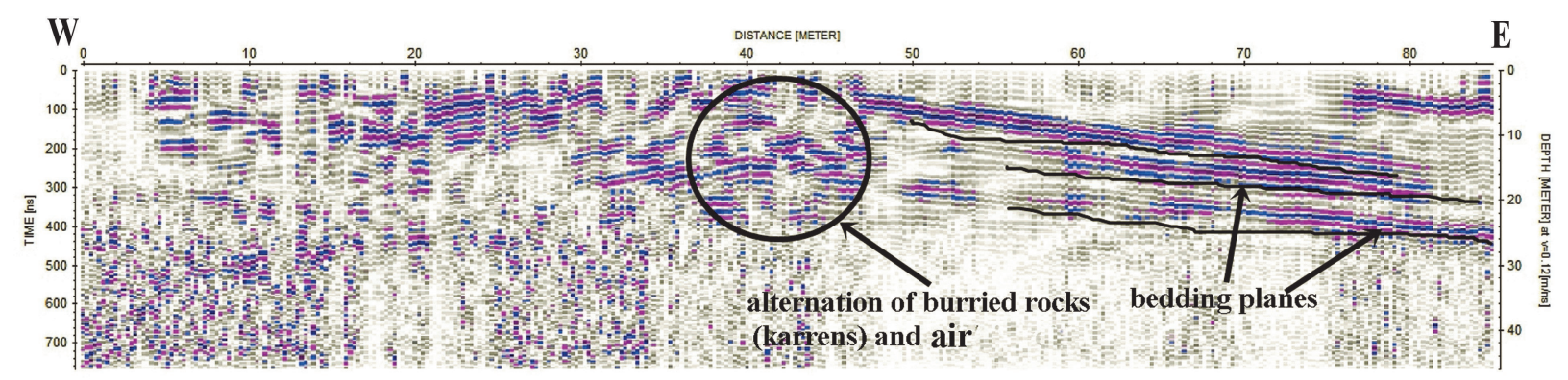

Figure 11. GPR profile at Site 2 on west-east direction.

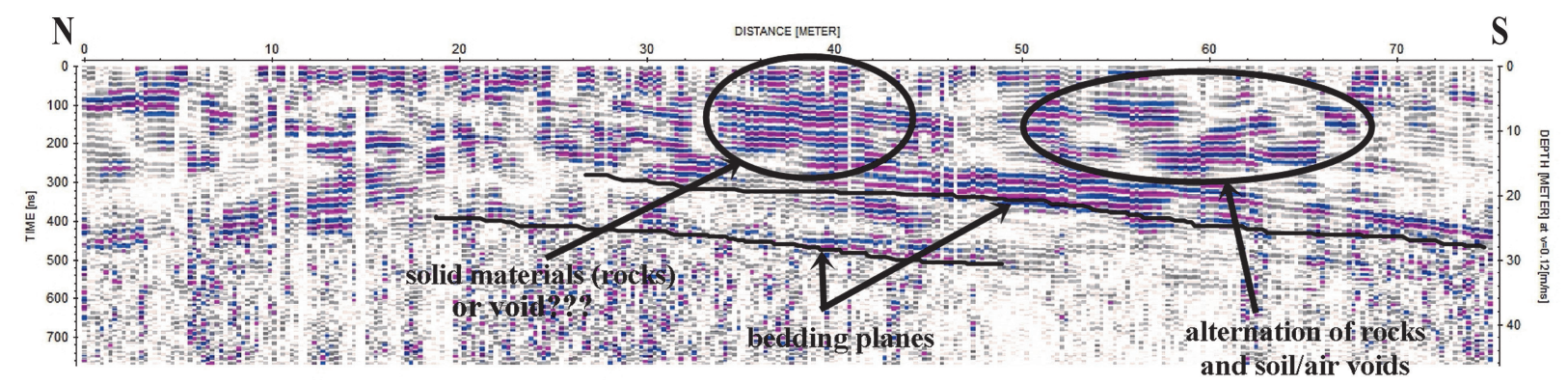

Figure 12. GPR profile at Site 2 on north-south direction. 
and if there could be certain cavities because the last 2 sinkholes (from West to East) present swallow holes.

The first radargram of this site (Figure 15), comprising all the three sinkholes is indicating very well the boundary into the underground of those depressions, the first sinkhole and the second one being more closely, and the boundary between the second one and the third one, that are separated by a dirt road. Also, we can notice that karrens present mostly on slopes of the first and the third sinkhole are observed on the GPR signals as buried rocks and also the radar signals indicate that in the middle of the third sinkhole, the largest and the deepest of these three depressions, could be a cavity or a void, based on previous GPR results in karstic areas (for example El-Qady et al., 2005; Gómez-Ortiz and Martín-Crespo, 2012). The funnel aspect of this sinkhole is favourable for a vertical cavity development. Again, we observed that countinous GPR signal that could be considered as bedding planes, but for the radargram presented in Figure 15, these are smaller than and not as obvious as in previous sinkholes.

We also obtained two radargrams on N-S orientation for sinkhole number 2 and 3 of this chain of sinkholes. Both

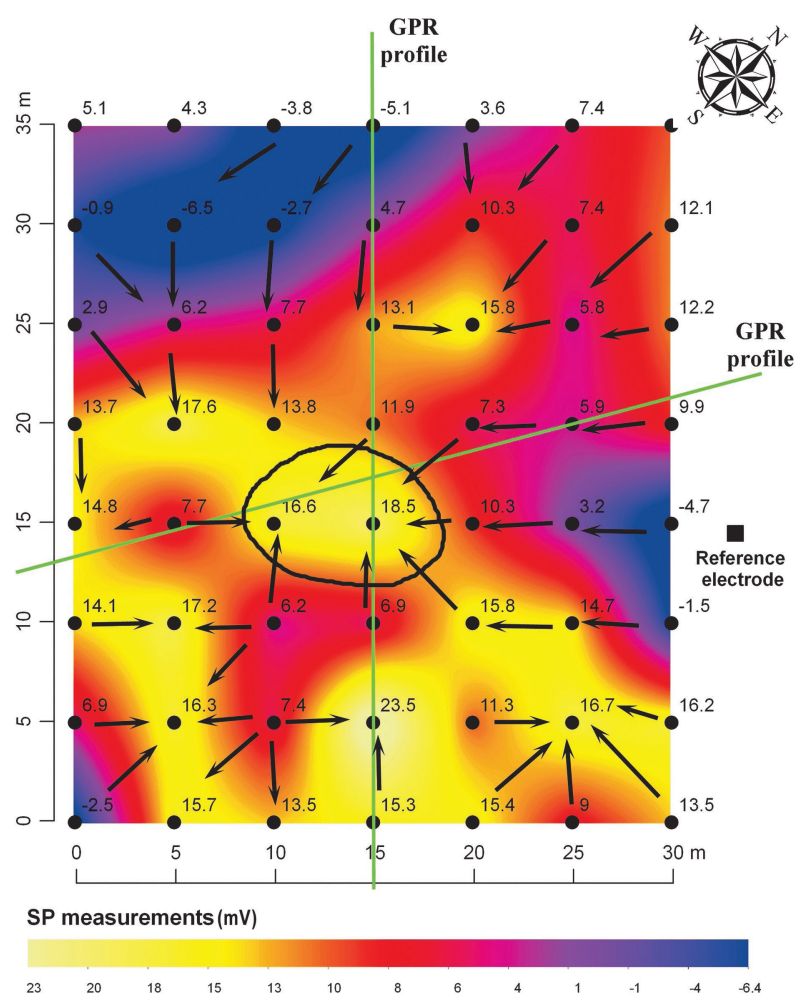

Figure 13. SP and GPR measurements at site 3.

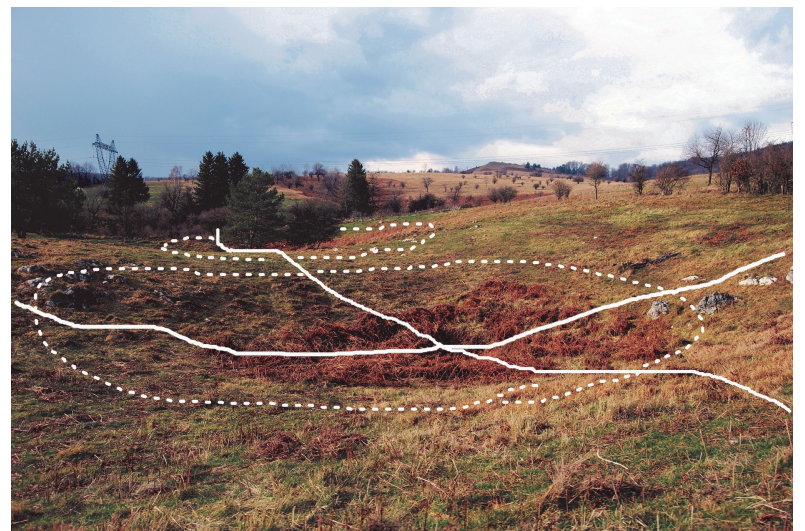

Figure 14. GPR measurements at Site 3 (Sinkhole 1 and Sinkhole 2 in this picture).

radargrams present a signal between 30 and 40 meters depth for Sinkhole 3 (Figure 16), a deeper sinkhole, and between 20 and 30 meters for Sinkhole 2 (less deep than Sinkhole 3). We consider that object as bedding planes, being present on both radargrams that are parallel to the terrain at a distance of several meters. The velocity was established based on previous study that applied GPR on limestone (Kadioglu and Ulugergerli, 2012; Apel and Dezelic, 2005).

Combining the SP measurements, with the GPR results, we can point out that it could be certain void in the middle of this site. We observe that the signal present in the middle of the last sinkhole in Figure 14 was obtained in the N-S profile (Figure 17). For the second sinkhole we notice that there are signs that we include in the buried rocks, but we rise the question if is not also clay padding, due to the fact that under that 10 meters there is no GPR signal (Figure 18).

\section{Discussion}

The results of SP measurements indicate in most of the cases that there is a direction in the water circulation (based on the negative values of SP measurements), but we also obtained positive values during the dry season, most of them being measured during August and September, after large dry periods. We observe that on the karstic plateaus, starting from May the soil was very dry and hard, with very small absolute values of SP, but also with positive values in the middle of the dolines, suggesting moisture accumulation areas.

GPR radargrams indicate bedding planes at depths between 20 and 30 meters, all these profiles being along north-south orientation. On one of the radargram we 


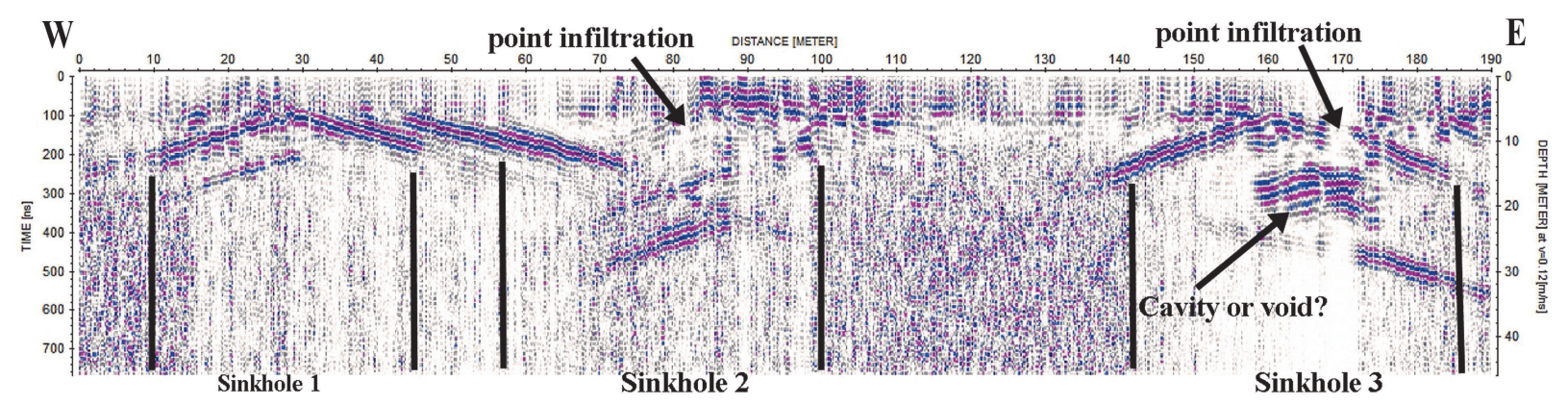

Figure 15. GPR profile at Site 3 for a chain of 3 sinkholes, from west to east.

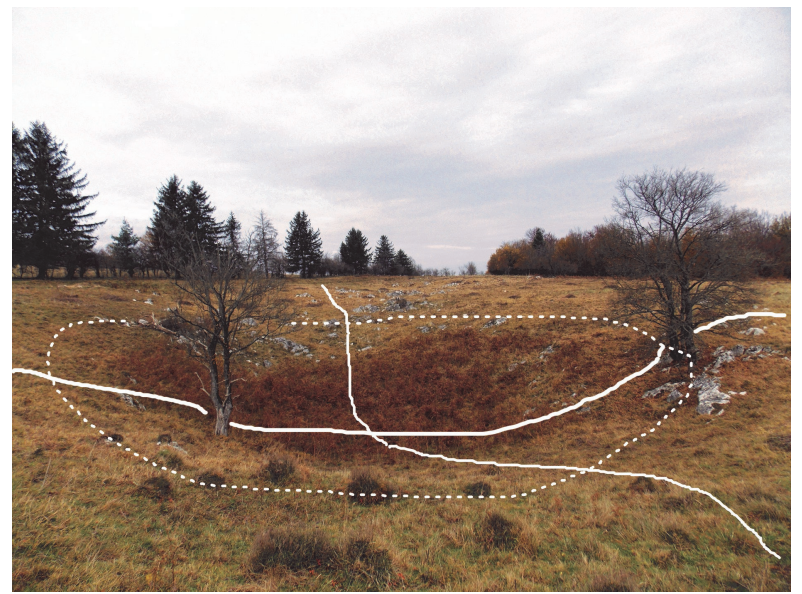

Figure 16. GPR measurements at Sinkhole 3 of Site 3.

observe a possible void or a cavity at 20 meters depth in the west to east profile. At the same depth we notice also on the north-south profile that the GPR signal point out an anomaly in the underground.

There are two profiles that are pointing out some discontinuities and possible cavities. One of these profiles was measured over a chain of three sinkholes and this profile at between 6 meters and 25 meters depth, shows some anomalies that indicate differential radar signal that we associate to an object as micro-tectonic features. The homogeneous aspect of radargrams indicates that these zones are not influenced by karst activity.
In this study we used two complementary geophysical methods, spontaneous potential (SP) and ground penetrating radar (GPR), applied in 5 sinkholes with a funnel shaped aspect. Four of these sinkholes are circular and one of them is elongated NW-SE direction. Three of the studied sinkholes are representing a chain of sinkholes orientated west-east. SP describes the surface drainage water indicating the tendency in the drainage direction or accumulation points. On the other hand, GPR describes the subsurface using the response of the materials or objects located in the underground to the signal sent by the radar antenna.

There are limitations in both methods, but they have been successfully applied in several sites for karst topography investigations (Jardani et al., 2007, 2009; Anchuela et al., 2008, 2009; Carpenter et al., 2013).

\section{Conclusions and Future Work}

GPR offers an image of the underground, showing possible bedding planes, mostly along north-south orientation. The north-south direction of the identified bedding planes are according to the main faults orientation of the studied area, NNE-SSW. Due to this aspect, we consider that the bedding planes are mostly observed on north-south profiles. Besides, in two GPR profiles, we could identify an object that could be a cavity, below and anomaly on SP grid.

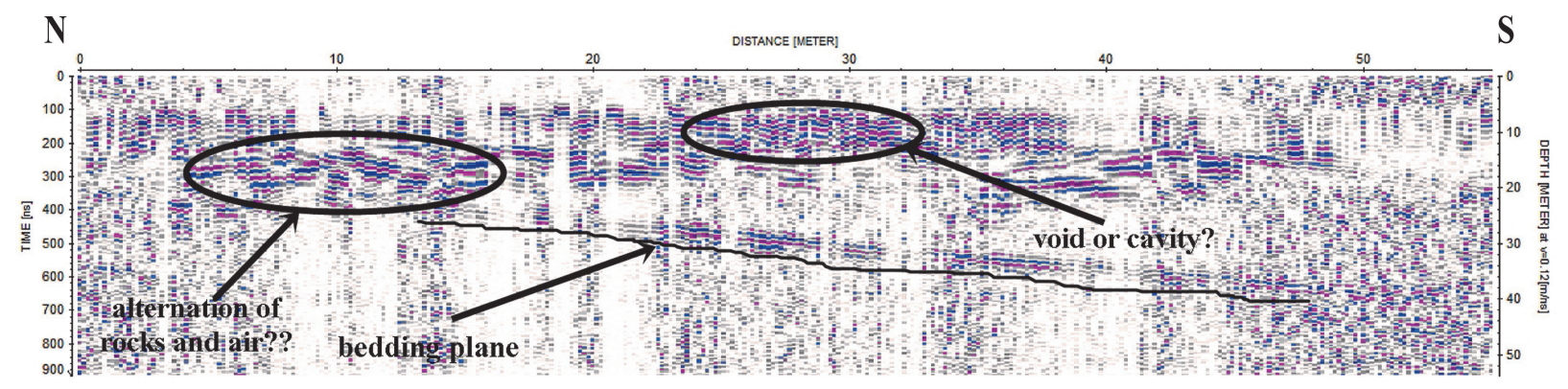

Figure 17. Sinkhole 3 of Site 3: GPR north-south profile. 


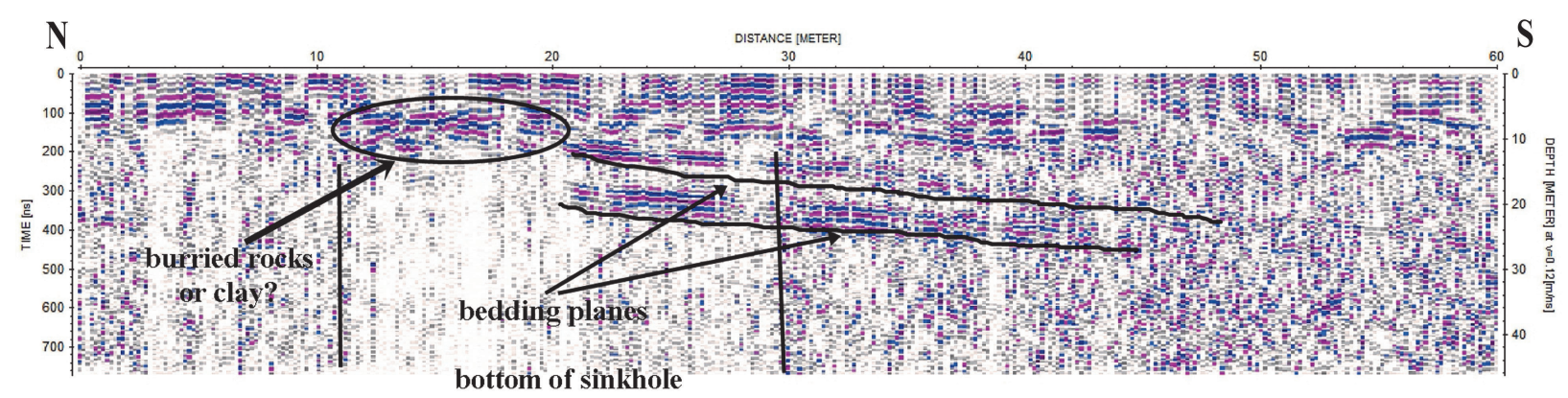

Figure 18. Sinkhole 2 of Site 3: GPR north-south profile.

Using SP and GPR methods we were able suggest that the bottoms of these depressions are retaining more humidity and soil. In addition, the GPR profiles outlined several subsurface "objects", at a depth ranging between 20 and 40 meters, which need a more thorough analysis.

Our future work is intended to enrich our field data using SP and GPR methods, to compare with our first results. Also, we intend to integrate electrical resistivity tomography (ERT) measurements in our analysis for a better subsurface characterization.

The ERT measurements that we intend to use in the future should provide a complete image of the subsurface, and with interpreted air-filled voids on the radargrams corresponding to very high resistivity zones.

\section{Acknowledgments}

We would like to thank those students and friends who helped us in the data field acquisition campaigns, who have been a real support in obtaining these results.

This work has been supported from the strategic grant POSDRU/159/1.5/S/133391, Project "Doctoral and Postdoctoral programs of excellence for highly qualified human resources training for research in the field of Life sciences, Environment and Earth Science" cofinanced by the European Social Fund within the Sectorial Operational Program Human Resources Development 2007-2013.

\section{References}

Al-fares W, Bakalowicz M, Guerin R, Dukhan M. 2002. Analysis of the karst aquifer structure of the Lamalou area (Herault, France) with ground penetrating radar, Journal of Applied Geophysics 51: 97-106.

Anchuela ÓP, Casas-Sainz AM, Soriano MA, PocovíJuan A. 2008. Mapping subsurface karst features with GPR: results and limitations. Environmental Geology 58 (2): 391-399. http://dx.doi. org/10.1007/s00254-008-1603-7.
Anchuela ÓP, Soriano APJMA, Casas-Sainz AM. 2009. Characterization of karst hazards from the perspective of the doline triangle using GPR - Examples from Central Ebro Basin (Spain). Engineering Geology 108 (3-4): 225-236. http:// dx.doi.org/10.1016/j.enggeo.2009.06.022.

Anchuela ÓP, Casas-Sainz AM, Soriano MA, PocovíJuan A. 2010. A geophysical survey routine for the detection of doline areas in the surroundings of Zaragoza (NE Spain). Engineering Geology 114 (3-4): 382-396. http://dx.doi.org/10.1016/j. enggeo.2010.05.015.

Anchuela ÓP, Juan AP, Casas-Sainz AM, Ansón-López D, Gil-Garbi DH. 2013. Actual extension of sinkholes: Considerations about geophysical, geomorphological, and field inspection techniques in urban planning projects in the Ebro basin (NE Spain). Geomorphology http://dx.doi. org/10.1016/j.geomorph.2013.01.024.

Apel DB, Dezelic V. 2005. Evaluation of high frequency ground penetrating radar (GPR) in mapping strata of dolomite and limestone rocks for ripping technique. International Journal of Surface Mining, Reclamation and Environment 19 (4): 260-275. http://dx.doi. org/10.1080/13895260500275418.

Artugyan L, Urdea P. 2014. Groundwater drainage monitoring and karst terrain analysis using Spontaneous Potential (SP) in Anina Mining Area (Banat Mountains, Romania). Preliminary study. Proceedings of Karst without Boundaries Conference. June 11-15, 2014, Trebinje Dubrovnik, p. 157-164.

Carpenter PJ, Adams RF, Lenczewski M, LealBautista, Rosa M. 2013. Ground-Penetrating Radar, Resistivity and spontaneous potential investigations of a contaminated aquifer near Cancún, Mexico, Proceedings of the 13th Multidisciplinary Conference on Sinkholes and the Engineering and Environmental Impacts of Karst, Carlsbad, New Mexico, p. 231-237.

Chalikakis K, Plagnes V, Guerin R, Valois R, Bosch FP. 2011. Contribution of geophysical methods to karst-system exploration: an overview. Hydrogeology Journal 19: 1169-1180. http:// dx.doi.org/10.1007/s10040-011-0746-x. 
Chamberlain AT, Sellers W, Proctor C, Coard R. 2000. Cave detection in limestone using ground penetrating radar. Journal of Archaeological Science 27: 957-964. http://dx.doi.org/10.1006/ jasc.1999.0525.

El-Qady G, Hafez M, Abdalla MA, Ushijima K. 2005. Imaging subsurface cavities using geoelectric tomography and ground-penetrating radar. Journal of Cave and Karst Studies 67 (3): 174-181.

Ford D, Williams P. 2011. Geomorphology Underground: The Study of Karst and Karst Processes. In: Gregory KJ, Goudie AS, editors. The SAGE Handbook of Geomorphology, SAGE Publications Ltd., London, 469-486.

Gómez-Ortiz D, Martín-Crespo T. 2012. Assessing the risk of subsidence of a sinkhole collapse using ground penetrating radar and electrical resistivity tomography. Engineering Geology 149-150: 1-12.

Guichet X, Jouniaux L, Catel N. 2006. Modification of streaming potential by precipitation of calcite in a sand-water system: laboratory measurements in the $\mathrm{pH}$ range from 4 to 12 . Geophysical Journal International 166: 445-460. http://dx.doi. org/10.1111/j.1365-246X.2006.02922.X.

Gutiérrez F, Galve JP, Lucha P, Castañeda C, Bonachea J, Guerrero J. 2011. Integrating geomorphological mapping, trenching, InSAR and GPR for the identification and characterization of sinkholes: A review and application in the mantled evaporite karst of the Ebro Valley (NE Spain). Geomorphology 134: 144-156.

Jardani A, Revil A, Santos F, Fauchard C, Dupont JP. 2007. Detection of preferential inflitration pathways in sinkholes using joint inversion of self-potential and EM-34 conductivity data. Geophysical Prospecting 55: 749-760.

Jardani A, Revil A, Barrash W, Crespy A, Rizzo E, Straface S, Johnson T. 2009. Reconstruction of the water table from self-potential data: A Bayesian Approach. Ground Water 47 (2): 213-227. http:// dx.doi.org/10.1111/j.1745-6584.2008.00513.x.

Jouniaux L, Maineult A, Naudet V, Pessel M, Sailhac P. 2009. Review of self-potential methods in hydrogeophysics. Comptes Rendus Geo-science 341 (10-11): 928-936. http://dx.doi.org/10.1016/j. crte. 2009.08.008.

Kadioglu S, Ulugergerli EU. 2012. Imaging karstic cavities in transparent 3D volume of the GPR data set in Akkopru dam, Mugla, Turkey. Nondestructive Testing and Evaluation 27 (3): 263-271.

Lange LA. 1999. Geophysical studies at Kartchner Caverns State Park, Arizona. Journal of Cave and Karst Studies 61 (2): 68-72.
Mafteiu M. 1991. Contributions to the investigation of the karst of Padiș area (Bihor Mountains, Romania) by means of resistivity measurements. Theoretical Applied Karstology 4: 65-76.

Mitrofan H, Povară I, Mafteiu M. 2008. Geoelectrical investigations by means of resistivity methods in karst areas in Romania. Environmental Geology 55: 405-413.

Nouioua I, Rouabhia AEK, Fehdi CH, Boukelloul ML, Gadri L, Chabou D, Mouici R. 2013. The application of GPR and electrical resistivity tomography as useful tools in detection of sinkholes in the Cheria Basin (northeast of Algeria). Environmental Earth Science 68: 1661-1672. http:// dx.doi.org/10.1007/s12665-012-1859-9.

Orășeanu I, Iurkiewicz A. 2010. Karst Hydrogeology of Romania, Ed. Federația Română de Speologie, Oradea. $444 \mathrm{pp}$.

Robert T, Dassargues A, Brouyère S, Kaufmann, O, Hallet V, Nguyen F. 2011. Assessing the contribution of electrical resistivity tomography (ERT) and self-potential (SP) methods for water well drilling program in fractured/karstified limestones. Journal of Applied Geophysics 75 (1): 42-53. http://dx.doi.org/10.1016/j. jappgeo.2011.06.008.

Reynolds JM. 1997. An Introduction to Applied and Environmental Geophysics 1st edition. Wiley.

Rozycki A, Fonticiella Ruiz JM, Cuadra A. 2006. Detection and evaluation of horizontal fractures in earth dams using the self-potential method. Engineering Geology 82: 145-153.

Sharma PV. 2002. Environmental and engineering geophysics. Cambridge University Press

Shofner GA, Mills HH, Duke JE. 2001. A simple map index of karstification and its relationship to sinkhole and cave distribution in Tennessee. Journal of Cave and Karst Studies 63 (2): 67-75.

Stevanovic Z, Dragisic V. 1998. An example of identifying karst groundwater flow. Environmental Geology 35 (4): 241-244.

Waltham T, Bell F, Culshaw M. 2005. Sinkholes and subsidence; karst and cavernous rocks in engineering and construction. Springer, Berlin, $382 \mathrm{p}$.

Zisman ED, PE, PG, M ASCE, Clarey D. 2013. If it's weight of hammer conditions, it must be a sinkhole?, Proceedings of the 13th Multidisciplinary Conference on Sinkholes and the Engineering and Environmental Impacts of Karst, Carlsbad, New Mexico, p. 45-52. 
